\title{
PROCESSOS DO COMÉRCIO EXTERIOR NA MOVIMENTAÇÃO DE MERCADORIAS: ASPECTOS OPERACIONAIS E PRATICAGEM
}

\author{
A. A. N. AMORIM \\ Instituto Federal de Educação, Ciência e Tecnologia do Rio Grande do Norte \\ a.augusto.amorim@gmail.com*
}

Artigo submetido em março/2016 e aceito em agosto/2016

DOI: 10.15628/empiricabr.2016.4262

\section{RESUMO}

Este estudo teve como objetivo compreender como os processos de comércio exterior na movimentação de mercadorias, seus aspectos operacionais e do serviço de praticagem, em conjunto, podem impulsionar o comércio exterior brasileiro, dado o fato de o setor terciário, em que está inserido, ser responsável por aproximadamente $70 \%$ do Produto Interno Bruto nacional. Assim, é evidente a necessidade de promover-se um processo contínuo de melhoria dos procedimentos operacionais relativos ao comércio exterior, especialmente aqueles que, direta ou indiretamente, relacionam-se com o transporte de mercadorias, incluindo o serviço de praticagem, tendo em vista a importância estratégica das exportações e importações para o desenvolvimento do país. Vários foram os autores que contribuíram para a base teórica da pesquisa, como Maluf (2000); Vieira (2006); Fonseca (2005); entre outros não menos importantes. Em termos de enquadramento metodológico, foi decidido recorrer à pesquisa qualitativa, de natureza exploratório-descritiva, utilizando-se como base para a coleta de dados a entrevista semiestruturada, com questionário como instrumento de coleta de dados. Após a análise dos dados coletados, concluiu-se que o serviço de praticagem constitui uma atividade essencial não só em natureza, bem como estratégica para o comércio exterior brasileiro, uma vez que a ausência da figura do prático para conduzir as embarcações durante o processo de embarque e desembarque de bens teria impacto na exportação e importação de produtos via modal marítimo, tornando-o inutilizável. Além disso, concluiu-se, também, que não só a estrutura do comércio exterior do Brasil está aquém do ideal, bem como os seus procedimentos operacionais constituem barreiras à sua consecução. Portanto, é necessário que tal estrutura seja revista, modernizada e flexibilizada, a fim de possibilitar economia de escala maiores margens de lucro e competitividade para o país.

PALAVRAS-CHAVE: Comércio Exterior. Praticagem. Transporte de Mercadorias. Procedimentos Operacionais.

FOREIGN TRADE PROCESSES IN CARGO HANDLING: OPERATIONAL ASPECTS AND PILOTAGE

\begin{abstract}
This study aimed to understand how the Foreign Trade processes in cargo handling, its operational aspects and the pilotage service, together, can boost the Brazilian Foreign Trade, given the fact that the tertiary sector, in which it is inserted, is responsible for about $70 \%$ of Brazil's Gross Domestic Product. Thus it is clear the need to promote a continuous process of improvement of operational procedures relating to Foreign Trade, especially those that directly or indirectly relate to the transport of goods, including pilotage, given the strategic importance of exports and imports to the country's development. Several authors contributed to the theoretical basis of this research, such as Maluf (2000); Vieira (2006); Fonseca (2005); and others no less important. In terms of methodological framework, it was decided to resort to qualitative research, of exploratory
\end{abstract}

and descriptive nature, using as a basis for data collection, semi-structured interviews, applying questionnaire as the data collection instrument. After analyzing the collected data, it was concluded that pilotage is an essential activity not only in nature, as well as strategic for Brazilian Foreign Trade, since the absence of the pilot to lead the vessels during the processes of loading and unloading of goods would impact the export and import of products waterway rendering it unusable. It also was concluded that not only the structure of Brazil's Foreign Trade is less than ideal, as well as its operating procedures constitute barriers to its own implementation. Therefore, it needs to be revised, modernized and made more flexible in order to propitiate economies of scale, higher profit margins and competitiveness for the country.

KEYWORDS: Foreign trade. Pilotage. Transport of Goods. Operational Procedures. 


\section{INTRODUÇÃO}

O comércio exterior é de grande importância para o desenvolvimento econômico, político e social de uma nação. Ele responde por grande parte do Produto Interno Bruto (PIB) dos Estados. Segundo dados disponibilizados pelo Ministério do Desenvolvimento, Indústria e Comércio Exterior - MDIC, no ano de 2013, o setor terciário respondeu por $68,5 \%$ do PIB brasileiro, bem como por $78,4 \%$ dos empregos formais no país.

No Brasil, as operações de comércio exterior são complexas, compostas por vários mecanismos, processos e ações que devem ser realizadas da melhor forma possível, de modo a garantir que as exportações e importações acarretem ganhos econômicos, além de projetar aqueles países cujo desempenho comercial é mais significativo, como atores globais no mercado internacional.

O comércio exterior brasileiro ainda se encontra em desenvolvimento, uma vez que as relações comerciais do país estiveram, por muito tempo, restritas ao mercado interno. Sua cultura exportadora é recente e está associada a décadas de políticas de substituição de importações, de seguidas crises cambiais e planos de estabilidade que sobrevalorizaram a taxa de câmbio, tornando o esforço exportador contemporâneo pouco atrativo e muito trabalhoso. Estabelecendo-se, assim, um viés anti-exportador na economia relativo à excessiva carga tributária, às regras cambiais e aos procedimentos burocráticos, que combinados e atuando simultaneamente, inibiram por longo tempo esforços sérios por parte de empresários brasileiros e demais indivíduos que almejassem atuar no mercado internacional. (FONSECA, 2005).

Para Fonseca (2005), a história do comércio exterior brasileiro é a raiz das discrepâncias do modelo brasileiro de comércio internacional, estando associada a altos custos logístico-portuários, com frete internacional, carga tributária excessiva, dificuldade de acesso a financiamentos e procedimentos burocráticos que freiam o desenvolvimento das operações comerciais.

Segundo a Confederação Nacional das Indústrias - CNI (2002), as principais dificuldades para a expansão das exportações brasileiras encontram-se nas operações aduaneiras, no custo portuário (principalmente quanto às atividades de estiva, capatazia e praticagem), no frete internacional, no difícil acesso ao financiamento e no sistema tributário. Ademais, ao que parece, as políticas governamentais quando se configuram como ineficientes, tendem a obstruir a construção e a percepção de cenários favoráveis, estes imprescindíveis ao comércio exterior que se almeja - contínuo, forte e competitivo.

A complexidade dos processos de comércio exterior no Brasil dificulta a inserção de empresas brasileiras no mercado internacional, pois, muitas delas se deparam com burocracia excessiva para a realização de registro de exportação e importação, entre outras operações inerentes às etapas de exportação e importação, além da carga tributária excessivamente onerosa e uma infraestrutura precária, que impacta tanto na velocidade de movimentação das mercadorias, quanto nos custos da cadeia produtiva.

Aliado à movimentação de mercadorias no âmbito do comércio exterior brasileiro encontra-se o serviço de praticagem. Este está intrinsecamente relacionado ao comércio exterior brasileiro e, portanto, à logística de transporte de cargas, uma vez que o Brasil é um país de proporções continentais e apresenta, segundo dados da Agência Nacional de Transportes 
Aquaviários - ANTAQ (2006), mais de 40 mil Km de vias navegáveis, dos quais 10 mil são utilizados para o comércio. (CONFEDERAÇÃO NACIONAL DOS TRANSPORTES, 2006).

Para que o comércio exterior brasileiro encontre um caminho de resultados efetivos e eficazes, parece fazer-se necessária a alteração de diversos paradigmas, a exemplo da rigidez formal dos processos, carga tributária excessiva, investimentos insuficientes em logística, bem como uma matriz de transportes desbalanceada, uma vez que o país sofre com a deficiente qualidade das rodovias, das ferrovias, dos portos e dos aeroportos. Todavia, para que se altere essa realidade, precisa-se fundamentar a análise nos procedimentos operacionais do comércio exterior, na movimentação de mercadorias e no papel que a praticagem exerce nesse contexto.

Levando-se em conta a importância da movimentação de mercadorias, seja para exportação e/ou importação, o serviço de praticagem e os processos operacionais do comércio exterior brasileiro, pretende-se, com o intuito de contribuir com a redução das discrepâncias no atual modelo de comércio exterior praticado no Brasil, responder à seguinte indagação: Como os processos do comércio exterior na movimentação de mercadorias, seus aspectos operacionais e do serviço de praticagem pode impulsionar o comércio exterior brasileiro?

Desta forma, almejando-se a solução do problema de pesquisa, estabeleceu-se o objetivo geral deste trabalho - Compreender como os processos do comércio exterior na movimentação de mercadorias, seus aspectos operacionais e do serviço de praticagem, conjuntamente, podem impulsionar o comércio exterior brasileiro - e, a partir deste, derivam-se quatro objetivos específicos: a) caracterizar os processos do comércio exterior brasileiro e os principais entraves que impedem seu avanço; b) verificar como se processa a relação entre praticagem e movimentação de cargas numa operação do comércio exterior; c) argumentar sobre como a redução das discrepâncias no modelo brasileiro de comércio exterior pode ocasionar aumento de competitividade ao setor; e d) identificar as limitações que as discrepâncias, na gestão do comércio exterior do Brasil, podem ocasionar na unidade do tempo.

\section{ESTRUTURA DO COMÉRCIO EXTERIOR BRASILEIRO: DOS PROCEDIMENTOS OPERACIONAIS AO SERVIÇO DE PRATICAGEM}

O mercado internacional tem tornado-se cada vez mais competitivo. Os clientes, cada vez mais exigentes, acirram disputa por oportunidades de negócio. Por esse motivo, o Brasil necessita aprimorar constantemente seus processos de comércio exterior, levando em conta, principalmente, os aspectos operacionais e de movimentação de cargas, bem como o serviço de praticagem.

Analisando-se a estrutura do comércio exterior brasileiro, seus processos e operações, percebe-se que as relações comerciais brasileiras em âmbito internacional estão bastante aquém do que é praticado em outros países. Dessa forma, é importante que questões, tais como a alta burocratização dos serviços relacionados às exportações e importações, aspectos econômicos e políticos do comércio do Brasil sejam revistos e adaptados aos padrões do mercado internacional eficazmente.

Outro aspecto de grande importância à pesquisa que será abordado nesta seção, é a questão do serviço de praticagem, suas características específicas, como este se processa, a figura do prático - profissional responsável por prestar tal serviço, suas funções e deveres, de forma a 
concatenar o máximo de informações sobre a temática e, desta forma, facilitar a compreensão acerca da questão da praticagem e sua relação com a movimentação de mercadorias e o comércio exterior.

Com o objetivo de construir o aporte teórico deste trabalho, pretende-se convidar autores renomados, cuja contribuição servirá para assegurar que os resultados obtidos ao longo da pesquisa sejam embasados em uma fundação sólida. Serão apresentados ao longo desta seção aspectos referentes aos processos do comércio exterior e o serviço de praticagem, relacionados à movimentação de mercadorias.

\subsection{PROCESSOS DO COMÉRCIO EXTERIOR}

O comércio exterior brasileiro apresenta-se dividido em três fases: etapa administrativa, etapa aduaneira e etapa cambial. Cada uma delas é administrada por órgãos anuentes e acessórios que contribuem com o adequado funcionamento dos processos de exportação e importação. 0 Quadro 1 resume as principais operações relacionadas a ambas as etapas:

Quadro 1: Etapas do processo de exportação.

\begin{tabular}{|c|c|}
\hline Administrativa & $\begin{array}{l}\text { - Negociação com importador; } \\
\text { - Obtenção de certificados adequados a situação (ex.: certificado de origem, } \\
\text { fitossanitário); } \\
\text { - Obtenção do Registro de Importação e Exportação (REI) e romaneio para transporte; } \\
\text { - Fatura pró forma; }\end{array}$ \\
\hline Aduaneira & $\begin{array}{ll}\text { - } & \text { Registro de Exportação; } \\
\text { - } & \text { Registro de Operação de Crédito; } \\
\text { - } & \text { Solicitação de Despacho (SD) e Declaração de Exportação (DDE); } \\
\text { - } & \text { Comprovante de Exportação (CE); } \\
\text { - } & \text { Declaração Simplificada de Exportação; } \\
\text { - } & \text { Licença de Exportação (LE); } \\
\text { - } & \text { Verificação da Mercadoria; } \\
\text { - } & \text { Averbação de Embarque e de Transposição na Fronteira; } \\
\text { - } & \text { Despacho Sumário; }\end{array}$ \\
\hline Cambial & $\begin{array}{ll}\text { - } & \text { Contratação do Câmbio; } \\
\text { - } & \text { Negociação ou entrega da moeda; } \\
\text { - } \quad \text { Liquidação; }\end{array}$ \\
\hline
\end{tabular}

Elaboração: Maluf (2000)

\subsubsection{Processo de exportação}

Segundo Maluf (2000), o processo de exportação se inicia com a prospecção de mercado identificar os possíveis compradores no mercado externo, seguido pela adequação da empresa aos requisitos legais do país de origem. Logo após, faz-se o contato com o comprador - contatar o possível comprador através de carta, telefone, e-mail, home page, fax, visita e/ou participação em feiras, missões comerciais, entre outras.

O próximo passo é a negociação - definir as condições de preço, entrega, embalagem, modalidade de pagamento, prazo de pagamento, quem irá se encarregar do transporte e seguro internacional, entre outras.

Após a negociação emite-se a fatura Proforma - emitir e enviar, após assinatura do Contrato de Compra e Venda Internacional, a fatura Proforma (Proforma Invoice) contendo 
especificação da mercadoria, incoterms (FOB, CIF, CFR, etc.), forma de pagamento, prazo de entrega, validade da cotação, modal de transporte, frete internacional, além das formalidades legais do país de destino.

A próxima etapa é a preparação da mercadoria para o embarque, seguida do registro e credenciamento - para operar no comércio exterior brasileiro, é necessário que a empresa efetue a sua inscrição no REI, junto à Secretaria de Comércio Exterior do Ministério do Desenvolvimento, Indústria e Comércio Exterior - MDIC.

Cumprida a etapa anterior, deverá ser efetuado o credenciamento junto à Secretaria da Receita Federal - SRF, onde se efetua o despacho aduaneiro. Logo em seguida, se dá o transporte internacional e, dependendo da modalidade de incoterm adotada (ou não), é possível estabelecer o pagamento do seguro. Depois de cumprida esta fase, decorre o despacho aduaneiro - no caso da contratação de despachante aduaneiro, o exportador providenciará a procuração para que aquele atue em seu nome.

Tão logo a etapa do despacho aduaneiro seja vencida, devem-se emitir os documentos fiscais, comerciais e financeiros (RE, nota fiscal e instrução de documentação, comprovante de exportação, além dos documentos comerciais - fatura comercial, romaneio de embarque, certificados e outros, bem como os documentos financeiros - saque, letra de câmbio, entre outros) antes do embarque.

O passo seguinte é o fechamento do câmbio que, conforme Maluf (2000) é centralizado, ou seja, o valor que o exportador recebe deve ser "trocado" por moeda nacional, por intermédio de uma instituição bancária, segundo o regramento brasileiro. Isto posto, toda empresa ou indivíduo que deseje atuar no comércio internacional deve procurar um banco autorizado para que este realize a operação de câmbio.

A chegada da mercadoria no destino, seguida do recebimento das divisas e liquidação do câmbio - operação de "troca" da moeda estrangeira pela nacional -, constitui o fim da exportação. Cada uma das fases de exportação é fiscalizada e monitorada por órgãos que possuem competência específica para realização dessas funções. A etapa comercial ou administrativa é de competência da Secretaria de Comércio Exterior (SECEX), do Ministério do Desenvolvimento, Indústria e Comércio Exterior. As funções da SECEX são: normatizar, supervisionar, orientar, planejar, controlar e avaliar as atividades de comércio exterior.

Segundo informações do portal SISCOMEX, as atividades da SECEX englobam sua participação em negociações de acordos comerciais internacionais do governo brasileiro, a promoção da cultura exportadora, deferimento dos atos concessórios de drawback, anuir operações de exportação e importação, promover o exame de similaridade para averiguação de produção nacional, compilar a balança comercial, promover a defesa comercial do país, entre outras.

A fase fiscal está a cargo da Secretaria da Receita Federal. São atribuídas à SRF, no âmbito do comércio exterior, as seguintes funções: administração dos tributos internos e do comércio exterior; gestão e execução das atividades de arrecadação, lançamento, cobrança administrativa, fiscalização, pesquisa e investigação fiscal e controle da arrecadação administrada; gestão e execução dos serviços de administração, fiscalização e controle aduaneiro; interpretação, aplicação e elaboração de propostas para o aperfeiçoamento da legislação tributária e aduaneira 
federal; subsídio à formulação da política tributária e aduaneira; e atuação na cooperação internacional e na negociação e implementação de acordos internacionais em matéria tributária e aduaneira.

A última fase de uma exportação é a cambial. É nela que ocorre a contratação da operação de compra, pelo exportador, da moeda nacional em troca das divisas. $O$ empresário brasileiro, após receber o pagamento pelo envio da mercadoria, encaminha-se a uma instituição autorizada pelo Banco Central do Brasil (BACEN) a atuar com câmbio. Banco e exportador fecham o contrato e, em seguida, dá-se a liquidação do câmbio.

O BACEN é responsável por fiscalizar e monitorar as atividades das entidades autorizadas a prestar serviços de compra e venda de moeda estrangeira e/ou nacional. Suas principais atribuições são: exercer a fiscalização das instituições financeiras e autorizar o funcionamento das instituições financeiras.

A Secretaria de Comércio Exterior, a Secretaria da Receita Federal do Brasil e o Banco Central do Brasil podem ser tidas como as instituições mais importantes quando do processo de exportação, pois cada uma delas exerce um tipo de controle, respectivamente, controle administrativo (SECEX), controle aduaneiro (SRFB) e controle cambial (BACEN).

\subsection{MOVIMENTAÇÃO DE MERCADORIAS NO BRASIL}

A movimentação de cargas é um dos processos mais relevantes para o comércio exterior, uma vez que é por meio do escoamento da produção que se obtém divisas. Para que as mercadorias recebam destinação correta, de modo que sejam transportadas desde o local onde são produzidas até o ponto de entrega, que pode ser uma rodovia, um porto ou aeroporto, é necessário levar em conta os custos com frete, seguros e o modal de transporte, entre outros.

Para determinar qual é o modo menos oneroso de transportar uma carga, deve-se considerar, também, exigências técnicas, sanitárias e fitossanitárias do produto, embalagem e rotulagem, formas de unitização, entre outros. De posse dos dados, o produtor deve escolher qual a melhor alternativa de transporte. Nesse momento, ele deve considerar qual o modal de transporte que melhor se adequa ás necessidades de prazos de entrega, segurança do produto, no sentido de evitar qualquer desgaste mecânico, dentre outros.

A matriz de transportes brasileira é desbalanceada. Por esse motivo, alguns modais de transporte são mais utilizados que outros. Isso se deve, em grande parte, à precariedade da infraestrutura nacional, além de investimentos insatisfatórios em logística. Isso implica diretamente nos custos produtivos, uma vez que, caso determinado modal de transporte possuísse estrutura adequada à condução de mercadorias durante operação específica, os custos com frete seriam reduzidos e, talvez, não fosse necessário recorrer a seguros.

Os principais modais de transporte no Brasil são o rodoviário, ferroviário, aquaviário, aéreo e, em menor quantidade o dutoviário. Cada um apresenta peculiaridades que se constituem em vantagens ou desvantagens para o transporte de cargas. A decisão dentre um ou outro deve levar em consideração os aspectos já mencionados, como o tipo de produto e prazos de entrega, o preço do frete e do seguro, entre outros. A seguir é mostrado um gráfico que representa a situação da matriz de transportes brasileira em 2013: 


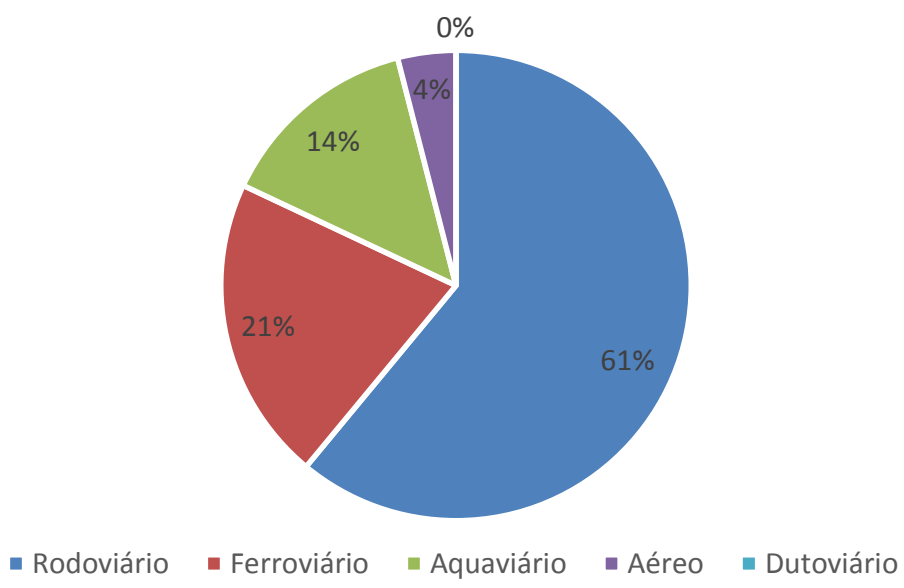

Gráfico 01 - Matriz de transportes brasileiro em 2013.

Fonte: SEBRAE (2013)

\subsection{REGULAMENTO ADUANEIRO DO BRASIL}

O direito aduaneiro compreende um conjunto de normas e valores que norteiam a política aduaneira de um país. Caracteriza-se pela intervenção pública na transação das mercadorias, do ou para o exterior, desenvolvendo-se um sistema de controle e proteção, por meio de barreiras alfandegárias, que são erguidas para proteger o produtor nacional.

Como instrumento normativo do direito aduaneiro, o regulamento aduaneiro compõe-se de um conjunto de normas jurídicas que regulam as relações comerciais de exportação e importação, além do transporte de mercadorias, pessoas e veículos, que entram ou saem do território nacional. O regulamento aduaneiro considera os regimes alfandegários em cada local, objetivando regulamentar e fiscalizar as atividades aduaneiras, controlando a tributação e as operações do comércio exterior.

Por sua vez, o regulamento aduaneiro designa um conjunto de ações implementadas pelo Estado, objetivando a regulação das exportações e importações e, para tanto, leva em conta o trânsito de indivíduos e mercadorias pela alfândega.

No Brasil, o decreto $n^{\circ}$ 6.759/09 regulamenta a administração das atividades aduaneiras e a fiscalização, o controle e a tributação das operações de comércio exterior. Essa norma introduz conceitos fundamentais para o comércio exterior, tais como: território aduaneiro; recintos alfandegados; terminais alfandegados; regime de trânsito aduaneiro; despacho aduaneiro; e drawback.

Segundo Bizelli (2006), o território aduaneiro compreende todo o território nacional. Porém, de modo a facilitar a compreensão da extensão e limites geográficos das áreas sob jurisdição do direito aduaneiro, divide-se o território aduaneiro em:

- Zona primária - abrange a área terrestre ou aquática, contínua ou descontínua, ocupada pelos portos alfandegados; área terrestre ocupada pelos aeroportos alfandegados; e área adjacente aos pontos de fronteira alfandegados.

- Zona secundária - compreende a parte restante do território aduaneiro, incluídas as águas territoriais e o espaço aéreo. 
Os recintos alfandegados são áreas demarcadas pela autoridade aduaneira competente, na zona primária dos portos organizados ou na zona secundária a estes vinculada, a fim de que nelas possam ocorrer, sob controle aduaneiro da Receita Federal, a movimentação, armazenagem e despacho aduaneiro de mercadorias provenientes do exterior, ou a ele destinado, inclusive sob regime aduaneiro especial1. De acordo com o art. $6^{\circ}$ do regulamento aduaneiro são recintos alfandegados:

- De zona primária: os pátios, armazéns, terminais e outros locais destinados à movimentação, assim como as aéreas reservadas à verificação de bagagens destinadas ao exterior ou dele procedentes; além das dependências de lojas francas.

- De zona secundária: os entrepostos, depósitos, terminais ou outras unidades destinadas ao armazenamento de mercadorias nas condições do inciso anterior; além das dependências de lojas francas; e, as dependências destinadas ao depósito de remessas postais internacionais sujeitas a controle aduaneiro.

Terminais alfandegados são áreas localizadas na zona secundária, que se destinam ao recebimento de cargas provenientes de importação ou de exportação, controladas pela Alfândega. Portanto, devem ser dotados de áreas para armazenagem, pátio de contêineres, perfeito controle de entrada e saída da carga e local para os serviços aduaneiros. O acesso da carga a esses terminais é feito através do regime de trânsito aduaneiro.

Por sua vez, o regime de trânsito aduaneiro consiste num benefício concedido tanto a importadores quanto exportadores. Por meio dele, as mercadorias que se destinam ao exterior e, aquelas que adentram no território nacional, transitam de um recinto alfandegado a outro, seja por via aérea, ou outro modal, considerando-se possíveis vantagens quanto ao desembaraço da carga, que possam ser auferidas ao se escolher entre um ou outro desses recintos.

O trânsito aduaneiro pode ser considerado uma operação relativamente simples, porém, devido à falta de conhecimento sobre os processos, recursos e legislações referentes ao comércio exterior e o direito aduaneiro, mesmo a mais simples das operações torna-se algo extremamente complexo.

Despacho aduaneiro é um procedimento fiscal que, segundo Vieira (2006), constitui-se num conjunto de atos praticados pelo agente da Receita Federal, cuja função é realizar o desembaraço aduaneiro, por meio do qual confere-se a procedência e exatidão das informações declaradas pelas partes envolvidas nas operações de importação e/ou exportação, em relação aos bens e documentos apresentados.

Ainda de acordo com Vieira (2006), desembaraço aduaneiro é a etapa final do despacho aduaneiro. A partir do cumprimento desta etapa, autoriza-se a entrega da mercadoria ao importador, ou o embarque dos bens que são objeto de exportação. No entanto, isso somente ocorre caso haja a devida conferência da mercadoria, cumprindo-se, portanto, a legislação tributária, além de serem identificados comprador e vendedor.

\footnotetext{
${ }^{1}$ Conforme informações provenientes do portal da RFB, o regime aduaneiro especial constitui-se num conjunto de operações do comércio exterior em que as exportações/importações gozam de benefícios fiscais como isenção, suspensão parcial ou total de tributos incidentes. Pode-se citar como exemplos: trânsito aduaneiro, drawback, dentre outras.
} 
Conforme o Decreto $n^{\circ} 646 / 922$, em seu artigo 1으. consideram-se atividades tipicamente relacionadas ao despacho aduaneiro de bens, veículos, entre outros, na importação ou na exportação, considerando-se o emprego de quaisquer dos modais de transporte, as seguintes:

- Preparação, entrada e acompanhamento da tramitação e de documentos que tenham por objeto o despacho aduaneiro, nos termos da legislação respectiva;

- Assistência a verificação da mercadoria na conferência aduaneira;

- Assistência a retirada de amostras para exames técnicos e periciais;

- Recebimento de mercadorias ou de bens desembaraçados;

- Solicitação de vistoria aduaneira;

- Assistência a vistoria aduaneira;

- Desistência de vistoria aduaneira;

- Subscrição de documentos que sirvam de base ao despacho aduaneiro;

- Ciência e recebimento de intimações, de notificações, de autos de infração, de despacho, de decisões e dos demais atos e termos processuais relacionados com o procedimento fiscal;

- Subscrição de termos de responsabilidade.

Exclui-se deste decreto a remessa postal internacional, uma vez que seu desembaraço pode ser feito por despachante aduaneiro, pessoalmente, por seu destinatário, ou por qualquer mandatário do destinatário (DECRETO N46/92, Parágrafo Único).

Ainda no âmbito do regulamento aduaneiro figura um mecanismo cuja finalidade é estimular as exportações brasileiras, por meio da desoneração de impostos relativos à importação de bens que estão vinculados ao processo produtivo das mercadorias que virão a ser exportadas.

O regime especial de drawback é concedido a empresas industriais ou comerciais, concedendo isenção ou suspensão do Imposto de Importação - II, do IPI, do ICMS, do Adicional ao Frete para Renovação da Marinha Mercante - AFRMM, além da dispensa do recolhimento de taxas que não correspondam à efetiva contraprestação de serviços, nos termos da legislação em vigor.

Após solicitar o benefício junto à Comissão de Política Aduaneira, o exportador brasileiro poderá escolher dentre as modalidades de drawback, aquela que mais se adapte às suas necessidades. As modalidades de drawback disponibilizadas aos produtores nacionais para incentivar as empresas e aqueles indivíduos que desejam ingressar no mercado internacional a desenvolver a prática de exportação são as seguintes:

- Suspensão: na importação e/ou aquisição no mercado interno de matérias primas, embalagens, insumos e componentes que serão utilizadas na industrialização de produto a ser exportado, com suspensão de tributos federais (II, IPI, PIS, COFINS, AFRMM) e isenção de ICMS, nos termos e condições previstos no Convênio ICMS 185/10.

- Isenção: é isenta de tributos federais (II, IPI, PIS, COFINS, AFRMM) a reposição de estoques de matérias primas, embalagens, insumos e componentes que foram utilizados na fabricação de produtos já exportados. O interessado deve comprovar as aquisições tributadas e o efetivo embarque das mercadorias exportadas.

\footnotetext{
${ }^{2}$ O Decreto $n^{\circ}$ 646/92 foi revogado pelo Decreto 7.213 de junho de 2010, que altera e acresce dispositivos ao Decreto $\mathrm{n}^{\circ}$ 6.759, de 5 de fevereiro de 2009, que regulamenta a administração das atividades aduaneiras, e a fiscalização, o controle e a tributação das operações de comércio exterior.
} 
- Restituição3: Devolução de tributos federais (II, IPI, PIS, COFINS, AFRMM) recolhidos quando da Importação de matérias primas, embalagens, insumos e componentes utilizados na fabricação de mercadorias comprovadamente exportadas.

Segundo a Secretaria da Receita Federal do Brasil, além das três modalidades supracitadas, o exportador brasileiro foi beneficiado com um benefício fiscal adicional: o drawback verdeamarelo (DBVA). Porém, o DBVA como é conhecido esta modalidade, pode ser enquadrado como um subtipo de drawback suspensão. Essa modalidade consiste na suspensão do IPI, PIS e COFINS nas aquisições de matérias-primas, produtos intermediários e materiais de embalagem, no mercado interno, por beneficiário do regime aduaneiro especial de drawback.

Além do Drawback Verde-Amarelo, o drawback suspensão compreende mais três subcategorias: drawback genérico - caracterizado pela discriminação genérica da mercadoria a importar e o seu respectivo valor; drawback sem cobertura cambial - quando não há cobertura cambial, parcial ou total, na importação; drawback solidário - quando existe participação solidária de duas ou mais empresas industriais na importação.

\subsection{O SERVIÇO DE PRATICAGEM NO BRASIL}

O Serviço de praticagem foi devidamente introduzido no Brasil, por meio do Decreto de 12 de junho de 1808, que além de criar a função de prático (ou piloto à época), estabelecia alguns critérios fundamentais para que esta pudesse ser exercida. Foi este instrumento legal que deu instaurou e oficializou a praticagem no Brasil. O texto narra o seguinte:

Porquanto pela Carta Régia de 28 de Janeiro proximo passado, fui servido permittir aos navios das Potencias alliadas e amigas da minha Côroa, a livre entrada nos Portos deste Continente; e sendo necessario, para que aquelles dos referidos navios que demandarem o Porto desta Capital não encontrem risco algum na sua entrada ou sahida, que haja Pilotos Praticos desta Barra, capazes e com os sufficientes conhecimentos, que possam merecer a confiança dos Commandantes ou Mestres das embarcações que entrarem ou sahirem deste Porto: hei por bem crear o logar de Piloto pratico da Barra deste Porto do Rio de Janeiro, e ordenar que sejam adimittidos a servir nesta qualidade os individuos que tiverem as circunstancias prescriptas no Regimento que baixa com este, assignado pelo Visconde de Anadia, do meu Conselho de Estado, Ministro e Secretário de Estado dos Negocios da Marinha e Dominios Ultramarinos, e que possam perceber pelo seu trabalho os emolumentos ahi declarados. O Infante $\mathrm{D}$. Pedro Carlos, meu muito amado e prezado sobrinho, Almirante General da Marinha, o tenha assim entendido e o faça executar. Palacio do Rio de Janeiro em 12 de junho de 1808 (BRASIL, 1808).

Apesar de ter sido o primeiro instrumento legal a versar sobre o serviço de praticagem e a introduzir a função de prático, no Brasil, o decreto de 12 de junho de 1808 foi apenas o marco inicial. Houve, desde então, muitos outros ampliaram a compreensão e importância desta atividade, tanto para a sociedade quanto para a Segurança Nacional.

\footnotetext{
3 Segundo informação contida no portal da SRF, o drawback restituição praticamente não é mais utilizado. O instrumento de incentivo à exportação, drawback, compreende, basicamente, as modalidades de isenção e suspensão.
} 
Em 1997 foi promulgada a Lei n. 9537/97, denominada Lei de Segurança do Tráfego Aquaviário - LESTA, que em seu artigo 12, define o serviço de praticagem como sendo um conjunto de atividades profissionais de assessoria ao comandante, requeridas por força de peculiaridades locais que dificultam a livre e segura movimentação da embarcação. Dessa forma, é possível depreender do artigo a importância deste serviço quando da necessidade de locomoção de determinada embarcação através de áreas de difícil acesso.

Além de tratar do relacionamento entre prático e comandante, a LESTA também se preocupou em classificar o serviço de praticagem como essencial e determinou que deve estar permanentemente disponível, impôs requisitos para a formação dos práticos, mediante exame e estágio de classificação, limitando sua inscrição a apenas uma Zona de Praticagem, condicionou a manutenção da habilitação do Prático à execução de um número mínimo de manobras e assegurou a todo Prático o livre exercício do serviço.

A Lei de Segurança do Tráfego Aquaviário também determinou que é de competência da Autoridade Marítima fixar o número de práticos necessários ao cumprimento do serviço de praticagem em cada ZP, além do preço do serviço em cada uma delas.

Em 1998 foi promulgado o Regulamento da Lei de Segurança do Tráfego Aquaviário RLESTA -, o qual definiu, no capítulo referente ao serviço de praticagem, sua constituição, englobando o prático, a lancha do prático e a atalaia. Além de determinar que a remuneração por essa atividade depende do emprego desses três elementos, já que ambos integram o serviço de praticagem, devendo o preço ser livremente negociado entre as partes interessadas, seja para conjunto ou para cada elemento separadamente.

Já no ano 2000, foi promulgada a NORMAM 12 - Norma da Autoridade Marítima para o Serviço de Praticagem -, cujo propósito era estabelecer diretrizes para o serviço de praticagem em águas jurisdicionais brasileiras (AJB), tais como: a competência do Diretor de Portos e Costas (DPC), como Representante Nacional da Autoridade Marítima, para regulamentar o Serviço de Praticagem, estabelecer as Zonas de Praticagem (ZP) em que a utilização do serviço é obrigatória ou facultativa e especificar as embarcações dispensadas do serviço.

A Norma da Autoridade Marítima para o Serviço de Praticagem, cujo propósito é estabelecer diretrizes para o serviço de praticagem em águas jurisdicionais brasileiras, assim como as citadas anteriormente, foi criada no ano de 2000. Além do objetivo de ratificar definições e diretrizes, determina ainda a competência da Diretoria de Portos e Costas (DPC) quanto ao estabelecimento das Zonas de Praticagem, em que a utilização do serviço é obrigatória ou facultativa, bem como a especificação das embarcações dispensadas do serviço de praticagem.

Segundo a NORMAM 12, zona de praticagem é uma área geográfica, que devido á peculiaridades locais, dificulta a livre e segura movimentação de embarcações, obrigando, desta forma, que os serviços de praticagem nessa área funcionem de forma ininterrupta. Compete a Diretoria de Portos e Costas estabelecer as Zonas de Praticagem.

A praticagem é organizada por Estado ou Região, a critério da Autoridade Marítima, em função de particularidades de cada local, considerando-se a frequência média de navios, a localização dos portos e terminais de outros aspectos pertinentes à segurança da navegação (PIMENTA, 2007, p. 75) 


\section{METODOLOGIA}

Esta pesquisa foi realizada com o intuito de analisar aspectos inerentes aos procedimentos operacionais do comércio exterior na movimentação de mercadorias e ao serviço de praticagem, de modo a compreender como cada um desses fatores, conjuntamente, podem impulsionar o comércio exterior brasileiro. Para tanto, adotou-se como tipologia de pesquisa o estudo qualitativo, de natureza exploratório-descritiva, de modo a relacionar os meios subjetivos e objetivos para uma maior compreensão da dinâmica do campo de estudo.

A técnica de coleta de dados adotada foi entrevista semiestruturada focalizada - que consiste num conjunto de questões predefinidas, porém, mantém-se certa liberdade para adicionar outras, consideradas fundamentais para se responder de forma adequada às indagações levantadas - e, para que esta seja conduzida de forma adequada, fazem-se necessárias certas qualidades ao pesquisador, como habilidade e perspicácia (MARCONI; LAKATOS, 2004, p.279).

Por meio da entrevista semiestruturada focalizada foram entrevistados vários profissionais relacionados à área de pesquisa. Todavia, aqueles que contribuíram de forma mais determinante para este trabalho foram uma professora do IFRN da área de logística, um prático atuante no Porto de Natal, bem como funcionários da CODERN. No entanto, devido a ausência de comprovação documental quanto a anuência dos entrevistados relativa à citação ou não de seus nomes no texto deste artigo, optou-se por não mencioná-los diretamente.

Fez-se necessário quanto aos procedimentos técnicos utilizados na construção do conhecimento, a adoção de pesquisa bibliográfica para "permitir ao investigador a cobertura de uma gama de fenômenos muito mais ampla do que aquela que poderia pesquisar diretamente" (GIL, 2008, p. 50), de pesquisa documental, por meio da qual se explorou os materiais disponíveis e interpretou-os conforme o objetivo da pesquisa (GIL, 2008), bem como da elaboração de questionários e/ou formulários, constituindo-se nas fontes primárias de informação. Ademais, utilizou-se da estatística descritiva para compreender matematicamente as relações entre as variáveis estudadas.

Quadro 2: Análise de Conteúdo dos aspectos inerentes à pesquisa.

\begin{tabular}{|c|l|l|}
\hline CATEGORIAS & \multicolumn{1}{|c|}{ SIGNIFICADO TEÓRICO } & \multicolumn{1}{|c|}{ SIGNIFICADO EMPÍRICO } \\
\hline Burocracia processual & $\begin{array}{l}\text { Burocracia é um conceito relativo ao } \\
\text { predomínio desproporcionado do } \\
\text { aparelho administrativo no conjunto da } \\
\text { vida pública ou dos negócios privados. }\end{array}$ & $\begin{array}{l}\text { A burocracia processual constitui-se num } \\
\text { dos principais entraves ao comércio } \\
\text { exterior brasileiro, tendo em vista a } \\
\text { lentidão dos processos, a rigidez formal e } \\
\text { legal. }\end{array}$ \\
\hline Praticagem & $\begin{array}{l}\text { É um serviço, ininterrupto, de auxílio ao } \\
\text { navegante, disponível em áreas onde } \\
\text { existem dificuldades ao livre e seguro } \\
\text { trânsito de navios. }\end{array}$ & $\begin{array}{l}\text { O serviço de praticagem, apesar de não } \\
\text { comércio exterior, tem grande importância } \\
\text { na movimentação de cargas. }\end{array}$ \\
\hline Modais de Transporte & $\begin{array}{l}\text { São os meios, por meio dos quais, as } \\
\text { mercadorias são transportadas, } \\
\text { distribuídas e entregues no seu local de } \\
\text { destino. }\end{array}$ & $\begin{array}{l}\text { A matriz de transportes brasileira } \\
\text { encontra-se desbalanceada, o que impacta } \\
\text { negativamente o comércio exterior } \\
\text { brasileiro. }\end{array}$ \\
\hline Planejamento logístico & $\begin{array}{l}\text { É uma ferramenta estratégica de } \\
\text { suporte, necessária para aumentar a a } \\
\text { eficiência da cadeia de suprimentos. }\end{array}$ & $\begin{array}{l}\text { A falta de um planejamento logístico eficaz } \\
\text { eficiente reduz a competitividade do } \\
\text { comércio exterior do Brasil. }\end{array}$ \\
\hline
\end{tabular}

Elaboração: Amorim (2015) 
Com vistas ao tratamento das informações coletadas, implementou-se a análise de conteúdo que, segundo Antônio Joaquim Severino (2011, p.121), "é uma metodologia de tratamento e análise de informações constantes de um documento, sob a forma de discursos pronunciados em diferentes linguagens: escritos, orais, imagens, gestos. Um conjunto de técnicas de análise das comunicações. [...] Envolve, portanto, a análise de conteúdo das mensagens, os enunciados dos discursos, a busca do significado das mensagens".

Como forma de possibilitar melhor entendimento acerca do que foi analisado, optou-se por esboçar um quadro de categorias de análise dos principais objetivos da pesquisa.

\section{ANÁLISE DOS RESULTADOS}

Nesta seção, apresenta-se o resultado obtido via análise dos dados coletados por meio de fontes primárias (entrevista semiestruturada, utilizando-se, para tanto, de um questionário de perguntas previamente formuladas, cujo objetivo era conduzir o entrevistado a contribuir o máximo possível com a obtenção das informações referentes à elucidação do problema de pesquisa) e fontes secundárias (consulta a sítios da internet, livros, artigos, entre outros).

Para melhor compreensão dos dados obtidos, o esforço de análise será dividido em duas fases: análise dos dados coletados; e tratamento dos resultados, inferência e interpretação, com base em conceitos correlatos à temática. Assim, com o auxílio das fontes secundárias pretende-se, nesta seção, aglutinar as informações coletadas por meio da entrevista com as obtidas em âmbito teórico-acadêmico.

\subsection{ANÁLISE DOS DADOS COLETADOS}

Segundo os dados concatenados ao longo deste trabalho, é possível perceber que, mesmo na atualidade, ainda existem fatores que impactam negativamente a condução e operacionalização do comércio exterior brasileiro. São fatores de natureza burocrática, fiscal, de planejamento governamental, de investimentos insuficientes e ineficientes em logística e, até mesmo, de pouca disseminação das informações relativas aos segmentos de exportação e importação de produtos. Isso pôde ser verificado, também, por meio da resposta fornecida por um dos entrevistados ao questionário, representada a seguir:

\footnotetext{
"Considero que os maiores problemas para a exportação brasileira são formados pela combinação de dois desses fatores apontados nas suas opções (a; b), que são o excesso de burocratização nos processos de comércio exterior e a tributação incidente sobre as mesmas que reduz a competitividade dos nossos produtos frente a outros países. Os investimentos em logística são insatisfatórios, mas a burocratização alfandegária e aduaneira, assim como a nossa carga tributária, na minha opinião, seriam os problemas mais significativos, bem como são os principais limitantes, do ponto de vista negativo, para as exportações em todo o Brasil" (Entrevistado, 2015).
}

Os dados obtidos por meio da entrevista corroboram com a ideia de que inexiste uma cultura exportadora moderna e consolidada no Brasil. Tal fato, segundo Fonseca (2005), contribui para o desenvolvimento de um viés antiexportador. Mesmo assim, existe por parte da iniciativa 
privada, uma tentativa de internacionalizar empresas com o intuito de obterem-se novas fontes de receitas, tendo em vista o cenário político e econômico atual.

Apesar disso, percebe-se o esforço da maioria do empresariado brasileiro para exportar e/ou importar mercadorias do exterior, buscando agregar valor e competitividade ao seu negócio.

Além do excesso de burocratização referente aos processos do comércio exterior, de tributação excessiva, da baixa disseminação de informações sobre as operações de exportação e importação e sobre os órgãos anuentes e intervenientes no comércio exterior, outro fator que tem frustrado esforços por parte dos empresários e demais indivíduos que almejam atuar nessa área é, sem dúvida, a estrutura logística ineficaz, ineficiente, insuficiente, seja por falta de investimentos necessários ou pela inexistência de planejamento necessário ao desenvolvimento de uma infraestrutura coerente com a demanda nacional e internacional por produtos. Isso pôde ser verificado após entrevista realizada com profissional da área logística, reproduzida a seguir:

\footnotetext{
"Sim. Para aumentar a competitividade brasileira nas exportações existe a necessidade de ampliação de espaços para a atracação de navios e o aumento do calado em diversos portos brasileiros. Também é necessário aumentar os espaços de armazenamento, bem como reduzir os custos de armazenamento. Outro ponto essencial é uma melhoria no gerenciamento dos processos de movimentação e liberação das cargas, com o uso de trâmites e equipamentos mais rápidos e eficientes. A exportação brasileira tem tempos de ciclo maiores que o de outros países o que impacta negativamente. Em logística, tempo é dinheiro. Tempo significa redução de custos que incidirão sobre as mercadorias que serão vendidas, assim como, impactam na melhoria da prestação de serviços na cadeia de suprimentos. No mundo todo, o tempo de ciclo de uma mercadoria é um dos pontos essenciais para a competitividade e nesse quesito, o Brasil em virtude da sua burocracia e do gerenciamento dos processos de armazenagem e movimentação de cargas perde para diversos outros países. Portanto, para aumentar a agilidade são necessários grandes investimentos em infraestrutura de estradas, portos, aeroportos e ferrovias. No entanto, existem algumas questões de ordem de gestão que estão atrapalhando o processo e que podem ser melhorados sem grandes investimentos, como a racionalização dos processos de exportação, a fim de buscar trâmites mais simples e ágil" (Entrevistado, 2015).
}

Além dos entraves já mencionados, outros fatores impactam negativamente na expansão das exportações brasileiras, tais como: as operações aduaneiras, no custo portuário (principalmente quanto às atividades de estiva, capatazia e praticagem), no frete internacional, no difícil acesso ao financiamento e no sistema tributário. Aliado a isso, estão as políticas governamentais que, se configuradas insatisfatoriamente, tendem a obstruir a construção e a percepção de cenários favoráveis, estes imprescindíveis ao comércio exterior que se almeja isento de intermitência.

Percebe-se, quanto à influência da logística nos resultados do comércio exterior, uma interação desagregativa entre Estado e setor privado. Isto, para o comércio exterior brasileiro, não é nada interessante, uma vez que para superar as limitações desenvolvidas ao longo dos séculos e moldar uma cultura exportadora eficaz e consciente, é preciso aliar políticas governamentais eficientes a investimentos e iniciativa do setor privado nas práticas de exportação e importação, para que, dessa forma, haja aumento da competitividade e maior lucratividade no setor. Resposta 
fornecida ao instrumento de coleta de dados, por um dos entrevistados, enfatiza a importância da integração entre Estado e setor privado:
"Muito precisa ser melhorado em relação as atividades portuárias e a movimentação interna dessas cargas em continente brasileiro, que requerem investimentos que precisam de horizontes de tempo bem maiores para se igualar a países que são de classe mundial em serviços logísticos de exportação. Inicialmente, o ideal seria incentivar maior integração entre as ações do governo e das empresas privadas relacionadas à logística portuária e ao comércio exterior" (Entrevistado, 2015).

Outra questão que se configura em entrave ao comércio exterior brasileiro é a dos modais de transporte. Tendo em vista as proporções continentais do país, não é de se admirar que possua uma malha aquaviária tão extensa, além de milhares de quilômetros de rodovias. Porém, não foram feitos os investimentos necessários para o desenvolvimento das ferrovias como alternativa viável, o que se denota como um entrave histórico, considerando que ultrapassa ao menos seis décadas.

O modal ferroviário poderia alavancar as importações brasileiras, além de minimizar de forma contundente os custos de movimentação e distribuição de cargas advindas dos portos e aeroportos. Os portos brasileiros, ainda hoje, não são capazes de suprir eficientemente a demanda portuária.

$\mathrm{Na}$ expectativa do comércio exterior, com características de dinamicidade e lucratividade, é necessário que num país com uma malha aquaviária tão extensa quanto a brasileira, realizem-se amplos investimentos em logística portuária, que compreende: ampliação da estrutura física atual, modernização do maquinário, contratação de pessoal cada vez mais qualificado e especializado, implementação de tecnologias e técnicas sofisticadas, entre outros.

Dentro do contexto da movimentação de mercadorias, o serviço de praticagem é fundamental, pois é por meio dele que as cargas que são transportadas em embarcações via modal marítimo chegam até o porto (importação) e, inversamente, saem do porto até os navios (exportação). Várias são as razões que justificam a atuação profissional do prático nesse contexto de objetivarem-se aspectos facilitadores à prática contínua e sustentável do comércio exterior.

A atuação do prático é fundamental, haja vista a sustentabilidade das ações mencionadas, transcende à ação sustentável do meio ambiente. Isto porque, o assessoramento prestado por esse mencionado profissional ao comandante, na condução segura do navio em áreas de navegação restrita ou sensíveis, tende a corroborar para a preservação ou, ao menos, para a minimização de danos, possivelmente causados ao meio ambiente, pelo simples fato do deslocamento da embarcação. Outros exemplos poderiam ser citados, em que pese a probabilidade da ocorrência de acidentes como, por exemplo, um encalhe que acarretaria atrasos, com prejuízos diversos e pagamento de diversas multas, envolvendo seguros, entre outros. O papel do prático é, portanto, prover a movimentação do navio com segurança, a fim de permitir que as mercadorias sejam embarcadas/desembarcadas dentro do prazo. Ao responder o questionário acerca de praticagem, o entrevistado, o qual se designou pela letra " $X$ ", afirmou o seguinte:

"Sendo a praticagem uma atividade profissional de interesse para a segurança da navegação e realizada onde ocorram particularidades locais que dificultam a livre 
e segura movimentação do navio, considero de suma importância, senão imprescindível, a atividade do prático, pois, sendo um auxiliar técnico do Comandante da embarcação, concorre para que o navio efetue a sua manobra com segurança, possibilitando, assim, o embarque e desembarque de mercadorias. Embora o prático não tenha atuação direta na movimentação das mercadorias, um atraso do navio devido a algum acidente, como por exemplo, um encalhe, acarretaria atrasos, com prejuízos diversos e pagamento de diversas multas, envolvendo seguros, etc." (X, 2015.)

Comenta-se acerca de uma eventual extinção do serviço de praticagem, porém, segundo o entrevistado, caso isso viesse a acontecer, haveria um aumento exponencial nos valores de seguros. Isto tornaria a movimentação de mercadorias via modal marítimo muito mais onerosa, de tal forma que acabasse sendo reduzida a quantidade de cargas transacionadas nesse meio.

Atrela-se à essa conjuntura, o papel desempenhado pelos gestores públicos e gestores privados, o que influi diretamente sobre os ganhos e perdas do comércio exterior brasileiro. Destaca-se a influência das políticas governamentais de captação e liberação de recursos para investimentos diretivos, por sua vez implicando na modernização, seja dos portos, aeroportos, malhas rodoviárias e, que não se omita das ferroviárias, uma vez que dentre as opções logísticas configura-se como a de maior escassez de investimentos, como já mencionado. O gestor privado também pode contribuir com a aplicação de recursos para modernização da infraestrutura logística, tendo em vista que ao fazê-lo estará reduzindo custos globais com tempo de transporte, distribuição, manuseio, despacho e embarque e desembarque das mercadorias, além de reduzir o tempo de exportação e/ou importação. Atenta-se para o cenário global que incentiva nas suas propostas essa ação, visto a ênfase nas estratégias desenvolvidas na forma de parcerias públicoprivadas.

Os gestores públicos e privados também desempenham papel de destaque quanto ao serviço de praticagem. Para se tornar um prático é necessário um processo seletivo constituído por várias etapas, além de um estágio que varia de 12 a 18 meses. Ademais, de tempos em tempos, todos os práticos são obrigados a frequentarem cursos de atualização, onde ficam a par das últimas inovações. Algumas empresas de praticagem financiam cursos que são ministrados no exterior. Por sua vez, o papel do gestor público, e em menor escala do que o gestor do setor privado, é o de prover os meios necessários para que haja um controle eficaz e técnico daqueles que pretende ingressar numa Praticagem.

Quanto à forma como a movimentação de mercadorias, os processos do comércio exterior e o serviço de praticagem ocorrem, é necessário rever as práticas relacionadas com cada uma dessas operações, de modo a agregar valor e torná-las mais eficazes, eficientes e competitivas. Segundo o entrevistado, a palavra-chave, aqui, é "segurança". Para ele, um serviço se torna eficaz quando toda a cadeia que o envolve ocorre sem grandes percalços. Segurança nem sempre combina com rapidez. Eventuais atrasos às vezes são necessários levando-se em consideração as peculiaridades de cada Zona de Praticagem.

Tendo em vista a importância do serviço de praticagem na movimentação de mercadorias, é necessário observar algumas posturas que devem ser adotadas por aqueles que desejem ingressar nessa área, bem como aqueles que nela já atuem, mas agem de modo adverso, portanto, demandando contínuas revisões nas posturas e atitudes adotadas. Desta forma, é necessário que 
estes indivíduos tenham segurança no que fazem que sejam capazes de desenvolver seus trabalhos sem ceder às pressões externas, adotar posturas calmas e assertivas, manter um bom diálogo com todos os envolvidos (autoridade marítima, portuária, armadores, entre outros) e, manter-se atualizado na profissão, tendo em mente que ninguém é infalível, mas que a possibilidade de erros serem cometidos pode e deve ser minimizada.

\subsection{TRATAMENTO DOS RESULTADOS, INFERÊNCIA E INTERPRETAÇÃO}

As atividades de movimentação de mercadorias transacionadas nos portos, aeroportos, vias férreas, rodovias e dutovias, no Brasil, são de fundamental importância para o comércio exterior brasileiro, uma vez que se relacionam diretamente com as operações de exportação ou importação de bens. Nesse âmbito, percebe-se que, aliado à circulação e encaminhamento das cargas, está o serviço de praticagem, pois o prático, indivíduo responsável por prestar tal serviço, é responsável pelas atividades de assessoramento ao comandante de embarcações na condução e manobras de navios em áreas de navegação restrita ou sensíveis para o meio ambiente.

O comércio exterior brasileiro ainda apresenta diversos aspectos limitantes e restritivos, que reduzem a competitividade e lucratividade do setor. Fatores como excesso de burocratização, tributação excessiva, investimentos insatisfatórios em logística, baixo grau de disseminação das informações referentes ao comércio exterior, além de baixo conhecimento por parte daqueles que desejam atuar neste segmento impactam negativamente as atividades relacionadas com exportação e importação de mercadorias. E, portanto, reduzindo a frequência de utilização do serviço de praticagem.

O excesso de burocratização dos processos relacionados ao comércio exterior é percebido, principalmente, quando da obtenção de certificados, de registros de importação e exportação, de venda, de operações de crédito, solicitação de despacho e declaração de exportação/importação, licença de exportação, despacho aduaneiro, averbação da mercadoria, consolidação de documentos necessários, dentre outros. Esses fatores, associados a outros previamente mencionados, constituem-se em verdadeiros entraves à expansão e ao desenvolvimento desse setor tão importante e fundamental para a balança comercial do Brasil.

O Brasil também enfrenta problemas relativos aos baixos e ineficazes e ineficientes investimentos na modernização dos modais de transporte. Apesar de investimentos volumosos, tanto por parte do Estado quanto do setor privado, a realidade é que a infraestrutura brasileira continua bastante aquém do ideal. Desse modo, as operações relativas ao comércio exterior tornam-se mais caras, mais morosas e menos competitivas.

A precária infraestrutura brasileira e a falta de planejamento estratégico quanto à modernização logística do Brasil tornam a movimentação de mercadorias numa operação mais complexa do que ela deveria ser, caso as condições fossem mais favoráveis. Cabe aos gestores públicos e privados desenvolverem parcerias mais integradas e comprometidas com essa causa.

A atividade de praticagem embora não tenha relação direta com a movimentação das mercadorias, influi indiretamente em razão de fatores que podem diminuir ou atrasar o fluxo de mercadorias de embarcações para os portos e vice-versa, quando, por exemplo, um navio demora a atracar no porto devido a algum acidente, acarretando atrasos, com prejuízos diversos e pagamento de diversas multas, envolvendo seguros, etc. Mesmo que o papel do prático esteja 
limitado a prover a movimentação do navio com segurança, a fim de permitir que as mercadorias sejam embarcadas/desembarcadas dentro do prazo, sua atuação é fundamental para que as cargas sejam transacionadas da melhor forma possível. Tal fato contribui para redução de tempo de transporte, podendo se constituir em ganho de competitividade.

A praticagem está relacionada à movimentação de mercadorias, pois é, por meio do serviço do prático, que as mercadorias podem ser embarcadas e/ou desembarcadas com segurança. Porém, os processos de comércio exterior se relacionam, também, com o transporte, circulação, distribuição e destinação de bens. Desta forma, para que o comércio exterior brasileiro venha a se tornar mais competitivo é necessário modernizar a estrutura burocrática do Estado, reduzindo o excesso de burocratização, além de desoneração fiscal, entre outros.

\section{CONSIDERAÇÕES FINAIS}

O objetivo do presente trabalho era compreender como os processos do comércio exterior na movimentação de mercadorias, seus aspectos operacionais e do serviço de praticagem, podem impulsionar o comércio exterior brasileiro-, foi atingido plenamente.

Este estudo teve como objetivos específicos: caracterizar os processos do comércio exterior brasileiro e os principais entraves que impedem seu avanço; verificar como se processa a relação entre praticagem e a movimentação de cargas numa operação do comércio exterior; argumentar sobre como a redução das discrepâncias no modelo brasileiro de comércio exterior pode ocasionar aumento de competitividade ao setor; e identificar as limitações que as discrepâncias, na gestão do comércio exterior do Brasil, podem ocasionar na unidade do tempo. Foi possível analisar cada um deles, alcançando-se resultados favoráveis quanto ao proposto.

A caracterização dos processos do comércio exterior e identificação dos principais entraves que impedem seu avanço, foi possível graças à fundamentação teórica e pesquisa bibliográfica, além, é claro, dos dados obtidos por meio de questionário. Já a verificação quanto à forma como o serviço de praticagem e a movimentação de mercadorias se relacionam se deu, principalmente por meio das informações fornecidas pelo prático entrevistado, mas também, pela utilização das fontes secundárias.

Argumentar sobre como a redução das discrepâncias no modelo brasileiro de comércio exterior pode ocasionar aumento de competitividade foi, possivelmente, o objetivo mais complexo a se alcançar ao longo deste trabalho. Todavia, os conhecimentos adquiridos ao longo do curso, somados às informações contidas na fundamentação teórica, relatos do entrevistado e o próprio panorama atual da economia brasileira, tornaram possível concluir que a redução da rigidez e formalismo nos processos de comércio exterior, bem como a diminuição da carga tributária, aliados a um planejamento logístico eficaz e eficiente, elaborado e implementado em conjunto, pelo setor público e privado são capazes de conferir maior competitividade ao comércio exterior brasileiro, tornando as exportações brasileiras mais lucrativas e interessantes na percepção daqueles que desejam atuar nessa área.

Quanto ao objetivo relativo à identificação das limitações que as discrepâncias, na gestão do comércio exterior do Brasil, podem ocasionar na unidade do tempo: foi possível concluir que os representantes do poder público (Presidência da República, ministérios e secretarias), os burocratas (servidores públicos responsáveis por fornecer apoio técnico-administrativo aos 
representantes do poder público) e os representantes do setor privado (empresários, confederação das indústrias, entre outros) são corresponsáveis pela gestão do comércio exterior brasileiro. No entanto, pelo fato de os representantes do poder público possuírem prerrogativas que os conferem posição privilegiada quanto à tomada de decisão referentes ao comércio exterior, também recai sobre eles maiores exigências quanto ao cumprimento das normas e implementação dos projetos, bem como seus resultados.

Para realizar tal análise, foi efetuada uma revisão teórica sobre os principais tópicos pertinentes ao assunto, com ênfase nos processos do comércio exterior e no serviço de praticagem, aliados à movimentação de mercadorias. Além disso, aplicou-se, também, um questionário nos moldes de uma entrevista semiestruturada, de forma a obter informações com base em fontes não apenas secundárias, bem como primárias.

As informações obtidas por meio da entrevista semiestruturada aliadas à fundamentação teórica e às fontes secundárias permitiram que se chegasse a uma melhor compreensão sobre como os processos do comércio exterior na movimentação de cargas e o serviço de praticagem podem impulsionar a economia brasileira.

A motivação que levou à consecução deste trabalho relaciona-se ao caráter de urgência quanto à modificação do panorama atual do comércio exterior brasileiro. Haja vista o cenário econômico atual, caracterizado por crise no setor produtivo, aumento da taxa de desemprego, desaquecimento do mercado doméstico, entre outros, faz-se necessário que o empresário brasileiro passe a atuar cada vez mais no âmbito do comércio exterior. Para tanto, é necessário que os processos e operações relacionados às exportações de bens e serviços sejam simplificados, também é fundamental que haja desoneração da carga tributária, bem como investimentos mais eficientes e eficazes em logística, principalmente no tocante à matriz de transportes brasileira, objetivando-se ao balanceamento nos percentuais de utilização de cada modal, uma vez que as exportações e importações brasileiras constituem-se em atividades estratégicas ao desenvolvimento nacional.

Isto posto, a partir das constatações obtidas por meio desta atual pesquisa, novos desdobramentos já se mostram viáveis e necessários. Logo, sugere-se que novos estudos sejam realizados, investigando-se mais ponderadamente o efeito do aprofundamento da parceria público-privada sobre o comércio exterior brasileiro, suas estruturas e o serviço de praticagem.

Espera-se, também, que este trabalho possa fornecer maiores informações acerca do tema pesquisado de forma que a sociedade, os gestores públicos e privados, além do meio acadêmico, desenvolvam maior interesse pelas questões inerentes ao comércio exterior, seus procedimentos operacionais, a movimentação de mercadorias e o serviço de praticagem, no sentido de melhor compreender a dinâmica na qual eles se inserem, buscando sempre o aperfeiçoamento do comércio exterior brasileiro e o desenvolvimento do país.

\section{REFERÊNCIAS}

1. ANTAQ - Agência Nacional de Transportes Aquaviário; disponível em www.antaq.gov.br/ PortalPortos, acesso 20 de jul. 2015.

2. BRASIL. Decreto de 12 de junho de 1808. Cria o cargo de Piloto Prático no Rio de Janeiro e dá- 
Ihe regimento. Legislação Informatizada. Diário [da] República do Brasil, Rio de Janeiro, RJ, 12 de jun. 1808. Disponível em: <http://www2.camara.leg.br/legin/fed/decret_sn/anterioresa 1824/decreto-40182-12-junho-1808-572165-publicacaooriginal-95281- pe.html>. Acesso em: 17 jun. 2015.

3. BRASIL. Decreto no 6.759 , de 5 de fevereiro de 2009. Regulamenta a administração das atividades aduaneiras, e a fiscalização, o controle e a tributação das operações de comércio exterior. Legislação Informatizada. Diário Oficial, Brasília, DF, 5 de fev. 2009. Disponível em: http://www.planalto.gov.br/ccivil_03/_ato2007-2010/2009/decreto/d6759.htm Acesso em: 12 de jul. 2015.

4. BRASIL. Decreto no 646, de 9 de setembro de 1992. Dispõe sobre a forma de investidura nas funções de despachante aduaneiro e ajudante de despachante aduaneiro e dá outras providências. Legislação Informatizada. Diário Oficial, Brasília, DF, 15 de jun. 2010. Disponível em: http://www.planalto.gov.br/ccivil_03/decreto/1990-1994/D0646.htm Acesso em: 12 de jul. 2015.

5. BRASIL. Decreto no 7213 , de 15 de junho de 2010. Altera e acresce dispositivos ao Decreto no 6.759 , de 5 de fevereiro de 2009, que regulamenta a administração das atividades aduaneiras, e a fiscalização, o controle e a tributação das operações de comércio exterior. Legislação Informatizada. Diário Oficial, Brasília, DF, 15 de jun. 2010. Disponível em: http://www.planalto.gov.br/ccivil_03/_Ato2007-2010/2010/Decreto/D7213.htm\#art11 Acesso em: 12 de jul. 2015.

6. BRASIL. Portaria-Lei n. 9.537, artigo 4ㅇ, 11 de dezembro de 1997 (LESTA). Diretoria de Portos e Costas/Marinha do Brasil.

7. BIZELLI, João dos Santos. Importação: sistemática administrativa, Cambial e Fiscal. São Paulo: Aduaneiras, 2006.

8. CNI - Confederação Nacional da Indústria (Unidade de Integração Internacional - INTER). Os problemas da empresa exportadora brasileira. Brasília: MTE, 2002.

9. CONSELHO NACIONAL PRATICAGEM. Estação de praticagem - Atalaia. Rio de Janeiro. Disponível em: <http://www.conapra.org.br/?page_id=2315>. Acesso em: 18 jun. 2015.

10. CNT (2006) - Confederação Nacional do Transporte. Pesquisa Aquaviária - Portos Marítimos: Longo Curso e Cabotagem. Brasília: Confederação Nacional do Transporte. Disponível em: http://www.cnt.org.br, acessado em 20 de jun. 2015.

11. _ (2014) - Confederação Nacional do Transporte. O Sistema Ferroviário Brasileiro. Brasília: Confederação Nacional do Transporte. Disponível em: http://www.cnt.org.br, acessado em 20 de jun. 2015.

12. FONSECA, R. G. O Brasil tem uma cultura exportadora? Disponível em http://www.funcex .com.br/janela.asp?tp=2\&xcd=60>. Acesso em: 12 ago. 2015.

13. GIL, Antônio Carlos. Métodos e técnicas de pesquisa social. 6. ed. São Paulo: Atlas, 2008.

14. LAKATOS, Eva Maria; MARCONI, Marina de Andrade. Metodologia científica. 4. ed. São Paulo: Atlas, 2004.

15. MALUF, Sâmia Nagib. Administrando o Comércio Exterior do Brasil. São Paulo: Aduaneiras, 2000. 
16. MARINHA DO BRASIL. Normam-12/DPC 1a revisão: Normas da autoridade marítima para o serviço de praticagem. 2011. Disponível em: <https://www.dpc.mar.mil.br/normam/ N_12/normam12.pdf>. Acesso em 18 jun. 2015.

17. MDIC - Ministério do Desenvolvimento, Indústria e Comércio Exterior. Disponível em http://www.desenvolvimento.gov.br/sitio/camex/pee/plaAcao.php> Acesso em: 11 ago. 2015.

18. PIMENTA, Matusalém Gonçalves. Responsabilidade Civil do Prático. Rio de Janeiro: Lumen Juris, 2007.

19. PORTAL SISCOMEX. Secretaria de Comércio Exterior. Disponível em: http://portal.siscomex .gov.br/legislacao/orgaos/secretaria-de-comercio-exterior-secex Acesso em: 15 de ago. 2015.

20. SEBRAE - Serviço de Apoio às Micro e Pequenas Empresas. Transporte de Cargas: Modais e Segmentos. 2014. Disponível em http://www.sebraemercados.com.br/

21. Acesso em 3 de jan. 2016

22. SRF - Secretaria da Receita Federal do Brasil. Disponível em http://www.receita.fazenda.gov .br/aduana/drawback/regime.htm

23. Acesso em 20 jun. 2015

24. VIEIRA, Aquiles. Importação: práticas, rotinas e procedimentos. São Paulo: Aduaneiras, 2006.

\section{APÊNDICE}

QUESTIONÁRIO UTILIZADO PARA COLETA DE DADOS REFERENTES AO TRABALHO DE CONCLUSÃO DE CURSO SUPERIOR DE TECNOLOGIA EM COMÉRCIO EXTERIOR.

PARTE 1 - DADOS RELATIVOS AO ENTREVISTADO.

- Nome completo: "preferiu-se não mencionar"

- Idade do entrevistado (a): "preferiu não ser mencionado"

- Formação Acadêmica: "não houve menção"

- Formação Acadêmica em comércio exterior ou área afim: "não houve menção"

- Cargo que ocupa atualmente na empresa: prático; professor (a) universitário

- Tempo de atuação na empresa e no cargo que desempenha atualmente: "cerca de dez anos de exercício"

- Atuação em cargo relacionado à área de comércio exterior: "sim"

PARTE 2 - DADOS RELATIVOS À EMPRESA, ENTIDADE DE CLASSE OU ORGANISMO PÚBLICO ENTREVISTADO.

- Quantos práticos em exercício possuem em seu quadro de funcionários? "Dado não fornecido"

- É possível informar se já houve acidentes provocados por má prestação do serviço de praticagem, que tenha ocasionado perda total ou parcial de carga? "Dado não fornecido"

- Existe algum estudo quanto a esses possíveis prejuízos? "Dado não fornecido"

- Qual a frequência com que o serviço de praticagem é utilizado mensalmente neste porto? "Em torno de seis vezes ao mês" 
- Em que consiste a maioria das cargas? Há um cliente líder em envios e recebimentos? "Produtos agrícolas em sua maioria"

\section{PARTE 3 - DADOS RELATIVOS AOS PROCESSOS DE COMÉRCIO EXTERIOR E PRATICAGEM.}

1. Em sua opinião, qual aspecto limitante impacta mais negativamente o comércio exterior brasileiro?

a) Excesso de burocratização nos processos de comércio exterior.

b) Tributação excessiva.

c) Investimentos insatisfatórios em logística.

d) Baixo grau de disseminação das informações referentes ao comércio exterior, além de baixo conhecimento por parte daqueles que desejam atuar neste segmento.

e) Caso haja outro, em sua opinião, qual?

"Considero que os maiores problemas para a exportação brasileira são formados pela combinação de dois desses pontos apontados nas suas opções $(a ; b)$, que são o excesso de burocratização nos processos de comércio exterior e a tributação incidente sobre as mesmas que reduz a competitividade dos nossos produtos frente a outros países. Os investimentos em logística são insatisfatórios, mas a burocratização alfandegária e aduaneira, assim como a nossa carga tributária, na minha opinião, seriam os problemas mais significativos, bem como são os principais limitantes, do ponto de vista negativo, para as exportações em todo o Brasil. "

2. Qual a sua opinião acerca da influência do serviço de praticagem na movimentação de mercadorias no comércio exterior brasileiro?

"Sendo a praticagem uma atividade profissional de interesse para a segurança da navegação e realizada onde ocorram particularidades locais que dificultam a livre e segura movimentação do navio, considero de suma importância, senão imprescindível, a atividade do prático, pois, sendo um auxiliar técnico do Comandante da embarcação, concorre para que o navio efetue a sua manobra com segurança, possibilitando, assim, o embarque e desembarque de mercadorias. Embora o prático não tenha atuação direta na movimentação das mercadorias, um atraso do navio devido a algum acidente, como por exemplo, um encalhe, acarretaria atrasos, com prejuízos diversos e pagamento de diversas multas, envolvendo seguros, etc. Respondendo objetivamente, o papel do prático limita-se a prover a movimentação do navio com segurança, a fim de permitir que as mercadorias sejam embarcadas/desembarcadas dentro do prazo. Considero um ator importante, porém, não o único. "

3. Tem-se discutido sobre uma eventual extinção da atividade de praticagem. Com base nisso, em sua opinião, de que forma (positiva ou limitante) tal ação influenciaria na movimentação de cargas via modal marítimo?

“Não diria extinção, mas um maior controle pela Autoridade Marítima. O Serviço de Praticagem no Brasil foi privatizado em 1961, por decisão do Ministério da Marinha. Os serviços de praticagem são submetidos a rigorosos padrões técnicos estabelecidos pela Marinha, tendo a DPC como órgão normatizador. Hoje, tanto no Brasil, com em quase todos os portos do mundo, o serviço de praticagem é obrigatório, sendo facultativo, apenas para alguns casos específicos. Caso não fosse mais necessário o emprego dos práticos, quem assumiria os riscos? Haveria um aumento absurdo do seguro. Tornaria a movimentação de cargas via modal marítimo muito mais onerosas. "

4. Em sua opinião, maiores investimentos em infraestrutura, principalmente em logística portuária, poderia acarretar redução das discrepâncias no atual modelo de comércio exterior brasileiro? 
"Sim. Para aumentar a competitividade brasileira nas exportações existe a necessidade de ampliação de espaços para a atracação de navios e o aumento do calado em diversos portos brasileiros. Também é necessário aumentar os espaços de armazenamento, bem como reduzir os custos de armazenamento. Outro ponto essencial é uma melhoria no gerenciamento dos processos de movimentação e liberação das cargas, com o uso de trâmites e equipamentos mais rápidos e eficientes. A exportação brasileira tem tempos de ciclo maiores que o de outros países o que impacta negativamente. Em logística, tempo é dinheiro. Tempo significa redução de custos que incidirão sobre as mercadorias que serão vendidas, assim como, impactam na melhoria da prestação de serviços na cadeia de suprimentos. No mundo todo, o tempo de ciclo de uma mercadoria é um dos pontos essenciais para a competitividade e nesse quesito, o Brasil em virtude da sua burocracia e do gerenciamento dos processos de armazenagem e movimentação de cargas perde para diversos outros países. Portanto, para aumentar a agilidade são necessários grandes investimentos em infraestrutura de estradas, portos, aeroportos e ferrovias. No entanto, existem algumas questões de ordem de gestão que estão atrapalhando o processo e que podem ser melhorados sem grandes investimentos, como a racionalização dos processos de exportação, a fim de buscar trâmites mais simples e ágil. "

5. Você acredita que o comércio exterior brasileiro pode alcançar patamares de competitividade em nível comparativo ao de países como Alemanha, Estados Unidos da América e Japão entre 5-10 anos?

“Não. Para um horizonte temporal de 5 a 10 anos não temos como alcançar o nível de desenvolvimento de países como Alemanha e Estados Unidos. Muito precisa ser melhorado em relação as atividades portuárias e a movimentação interna dessas cargas em continente brasileiro, que requerem investimentos que precisam de horizontes de tempo bem maiores para se igualar a países que são de classe mundial em serviços logísticos de exportação. O nível de defasagem é tão alto que não considero adequado a comparação Brasil, EUA ou Alemanha como meta para o nosso desenvolvimento. Um exemplo simples, se refere ao modal de transporte de maior uso brasileiro que é o modal rodoviário, do qual não é possível fazer a mínima comparação entre as estradas brasileiras e as alemãs ou americanas."

6. Em sua opinião, qual o papel do gestor público e da iniciativa privada na construção de um modelo de comércio exterior eficiente?

“No que tange ao serviço de praticagem, para se tornar um prático é necessário um processo seletivo constituído por várias etapas, além de um estágio que varia de 12 a 18 meses. Ademais, de tempos em tempos, todos os práticos são obrigados a frequentarem cursos de atualização, onde ficam a par das últimas inovações. Algumas Empresas de Praticagem financiam cursos que são ministrados no exterior. Basicamente, o papel do gestor público, e em menor escala do setor privado, é o de prover os meios necessários para que haja um controle eficaz e técnico daqueles que pretende ingressar numa Praticagem. "

7. Em sua opinião, o que poderia ser agregado ao comércio exterior brasileiro, tendo em vista a movimentação de mercadorias e o serviço de praticagem, de forma a propiciar maior eficácia nos resultados?

"Diria que a palavra chave é "segurança", e um serviço se torna eficaz quando toda a cadeia que o envolve ocorre sem grandes percalços. Segurança nem sempre combina com rapidez. Eventuais atrasos às vezes são necessários levando-se em consideração as peculiaridades locais. "

8. Em sua opinião, como é a interação entre o prático e as autoridades portuárias (representantes do setor público)? Justifique sua resposta:

a) Excelente.

b) Bom. 


\section{c) Regular.}

d) Ruim.

e) Péssimo.

"Temos que ser parceiros, pois ninguém faz nada sozinho. Como citei, o interesse comercial não pode se sobrepor à segurança. No geral é bom, e quando existe algumas divergências, temos que superá-la através do diálogo."

9. Em sua opinião, como é a interação entre o prático e os armadores (representantes do setor privado). Justifique sua resposta:
a) Excelente.
b) Bom.
c) Regular.
d) Ruim.
e) Péssimo.

"Este sempre foi e sempre será um fator de eternas discussões, haja vista interesses antagônicos. Particularmente, no nosso caso, aqui em Natal, não temos tido maiores entraves, havendo inclusive, às vezes, reuniões com seus representantes onde se esclarecem dúvidas e outros assuntos de interesse. No geral, aqui temos tido um bom relacionamento."

10. Elenque, em sua opinião, ao menos cinco aspectos inerentes à sua própria iniciativa que contribuem para a realização da atividade de praticagem e, por conseguinte, ao desenvolvimento do comércio exterior brasileiro.

“Um bom profissional deve, no mínimo, reunir as seguintes características: Ter segurança naquilo que se faz; não ceder às pressões externas; procurar ter uma atitude calma e assertiva; manter um bom diálogo com todos os envolvidos (autoridade marítima, portuária, armadores, etc.); manter-se atualizado na profissão, tendo em mente que ninguém é infalível, mas que a possibilidade de erros serem cometidos podem ser minimizados." 